\title{
APPLICATION OF TERRESTRIAL LASER SCANNING (LIDAR) IN ROCK SLOPE STABILITY. AN EXAMPLE FROM NORTHERN GREECE
}

\author{
Ampatzi G. ${ }^{1}$, Chatzigogos N. ${ }^{2}$, Makedon M. ${ }^{1}$, Papathanassiou G. ${ }^{1}$ and \\ Marinos V. ${ }^{1}$ \\ ${ }^{\text {I} A r i s t o t l e ~ U n i v e r s i t y ~ o f ~ T h e s s a l o n i k i, ~ D e p a r t m e n t ~ o f ~ G e o l o g y, ~ 54124, ~ T h e s s a l o n i k i, ~ G r e e c e, ~ g a m p a ~}$ \\ tzi@geo.auth.gr,thomas@geo.auth.gr,gpapatha@gmail.com,marinosv@geo.auth.gr \\ ${ }^{2}$ Triger Geologists-Consultants, chatzi12@gmail.com
}

\begin{abstract}
The scope of this study is to investigate the failure mechanisms of the eastern coastal zone of Mount Athos, using the LiDar device for the 3D mapping of the structural features of the rock mass. Therefore emphasis was given to the study of the planes of discontinuities that can trigger potential failures. All slopes were scanned by LiDar device in order to capture their structure and especially the orientation and the spacing of the discontinuities. The data were processed in order to produce the microtectonic model of the slopes and evaluate the potential slope failures. Finally some remedial measures are proposed.The results and the reliability as well as the constrictions of the applied methodology are discussed for future applications.

Keywords: slope stability analysis, terrestrial laser scanning, LiDar, coastal erosion.

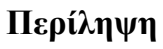

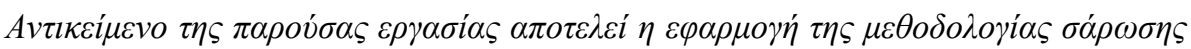

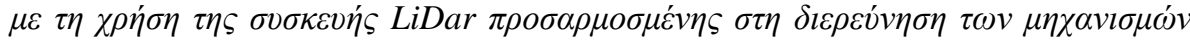

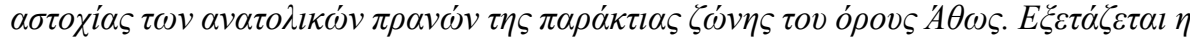

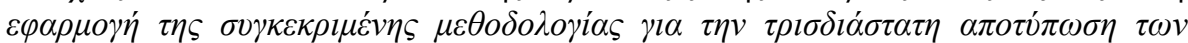

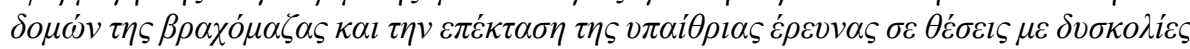

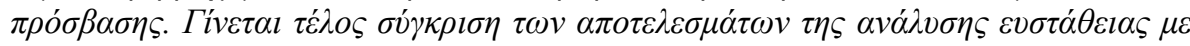

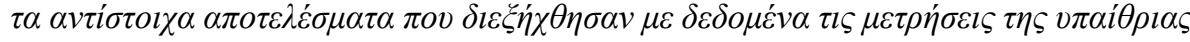

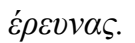

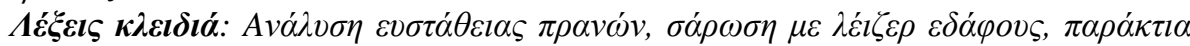
$\delta i \alpha ́ \beta \rho \omega \sigma \eta$.
\end{abstract}

\section{Introduction}

Engineering geological investigation of certain areas presents difficulties due to geomorphological and geological conditions which may hinder the collection of all necessary data. This occurs in case of steep or high slopes in areas with sharp topography that are inaccessible or consist of loose sediments which render the assess both difficult and hazardous.

The Light Detection and Ranging (LiDar) is a new technology device (Bitelli et al., 2004; Biasion et al., 2005; Abellan et al., 2006, Pesci et al., 2009) that offers three-dimensional information display in the field from a distance (Bauer et al., 2005; Rosser et al., 2005; Oppikofer et al., 2008a). The 
technique is based on laser pulse emission of radiation (UV, visible or near-infrared) through the atmosphere and recording of the backscattered laser radiation. The scattered light is collected by an optical lens and driven in the shooting and recording system. Detecting the returning pulses, the equipment records the time that it takes for them to go from the laser scanner to the ground and back. The distance between the laser scanner and the ground is then calculated based on the speed of light (Slob and Hack, 2004).

The first LiDar device was constructed in the early 1960s, shortly after the invention of the laser. It became widely known through the use of the mission Apollo 15, 1971, for mapping the lunar surface. In engineering geology it could be used in rock mass characterization, in slope/tunnel stability issues, in rock falls or in recording of movements with little evolution in time by considering geological formations as targets and recording their tectonic structures.

A pioneering study that detects precursory patterns in wide areas using LiDar device was made by Rosser et al. (2007), who observed a precursory pattern of small rockfalls leading to larger failures. Slob et al. (2002) used a DEM formed from LiDar points to measure the local face orientation across an outcrop surface. Sagy et al. (2007) quantitatively studied fault surface geometry with highresolution LiDar data. Bellian et al. (2005) provided a concise overview of LiDar and its application to outcrop studies. The promise of LiDar was discussed by McCaffrey et al. (2005).

The advantages of the device are numerous: The target can be a wide range of materials (rock, clouds, rain). Scanning can be performed from a distance even in inaccessible places, and exported results are of high-resolution. The most important is the high quantity and density of measurements (Monserrat and Crosetto, 2008). Finally, scanning and data processing consume less time. There are three types of equipment. The terrestrial which is mounted on a tripod, the mobile type on any vehicle or onboard and the airborne that uses an aircraft. For the present investigation a terrestrial LiDar scanner of Optech company was used with scanning distances specifications 3 to $1000 \mathrm{~m}$ and accuracy of $14 \mathrm{~mm}$. Figure 1 shows the device scanning the southern slope around the monastery.

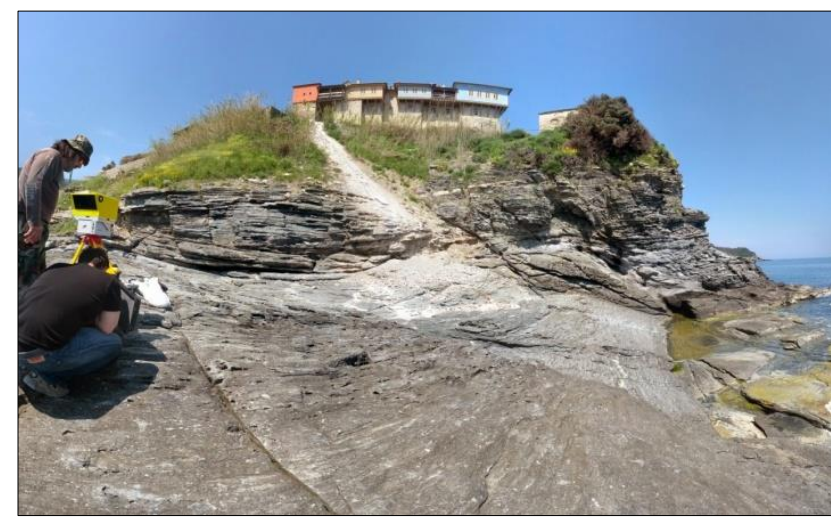

Figure 1 - The LiDar device used for the scanning of the slopes of the Pantocratora's Holy Monastery, Agio Oros (Triger Geologists-Consultants, 2014, personal communication).

\subsection{Rock slide background}

The area of research is located in the eastern peninsula of Halkidiki, called the Athos peninsula and specifically in the coastal zone of Pantokratora's Holy Monastery. Many rock fall events have occurred in the area in the past because of the steep morphology, the discontinuities of the rocks which are unfavorable to the inclination of the slopes and the influence of the sea which excavates the slopes' foot. The largest recorded incident occurred 40 years ago, which caused a landslide that moved the old cemetery of the Monastery into the sea. Continuous slides shaped the current landscape which is still quite steep and causes failures. 
The whole area has a strong morphology. The ground is mountainous and is often inaccessible because of the steep and high slopes but also due to the dense forest cover.

\subsection{Methodology}

The rock mass behaves anisotropically due to the persistence of specific systems of discontinuities. The application of Mohr-Coulomb criteria gives slopes of perfect stability but the reality is different as mentioned earlier. From in situ research it was found that all previous landslides occurred along surfaces of discontinuity. Consequently the study was focused to the geometry and their mechanical characteristics. The dip and dip direction of the slopes were obtained from the map and field observations, while three to five joint surfaces were measured in order to calibrate the LiDar results. Each slope of the area was scanned by the LiDar. This paper analyses the results of two specific slope directions.

The scanning images were edited with the aid of Split-FX (Split Engineering 2010) software in order to detect the orientation and spacing of all detected discontinuities at each of the two locations and analyze their impact in respect to the structural slope stability. For this scope, tectonic diagrams and kinematic analysis were performed, while a slope stability assessment in its case was carried out. Finally, some remedial measures are proposed.

\section{Geological setting}

Geotectonically the wider area lies mainly in Serbomacedonian mass and secondarily in the Perirodopiki zone in a small section at the southern end. The Serbomacedonian is composed of metamorphic rocks and is divided into two major series of rocks: the lower series of Kerdilia and the upper series of Vertiskos. Between the two there is a tectonic contact. The Athos peninsula belongs to the Vertiskos series.

According to Mountrakis (1985) it consists of a sequence of gneisses, mica schists and thin intercalations of marble, while the upper horizons and dominated by meta-gabbros, meta-diavases and amphibolites, derived from transformation of basic igneous rocks. Often serpentine layers interfere with tectonic contacts within other rocks. The rocks of Vertiskos series present an almandine metamorphic stage". This was reflected on the extract of the Geological map of IGME, sheet Athos Peninsula, 1:50.000.

The site specific area of the Monastery is a rocky hill at the end of a forested slope. Almost vertical slopes are formed next to the sea front with a maximum height of $30 \mathrm{~m}$. Geological mapping in the investigated area showed amphibolites with intercalations of pegmatite veins and mica gneiss (Figure 2). Cross-sections \#No.2 and \#No.9 reflect the geology, geometry and tectonic structure of the slopes (Figures 3-4).

The geological formations are considered impermeable. Ground water percolates through fractured or weathered rocks but discharged quickly since sound rock is present. Hence, no significant hydrostatic pressures are build within the rock mass. Three faults with NW-SE, SW-NE and E-W direction are crossing the Monastery's foundation bedrock.

The climate is affected by winds of NE direction and waves consist an erosive factor that undermines the foot of the slopes, removing load and shaping the general landscape. The climate is characterized by mild winters in the lower zones near the sea, while summers are dry. The rainfall in the area ranges from 600 to $800 \mathrm{~mm}$. 


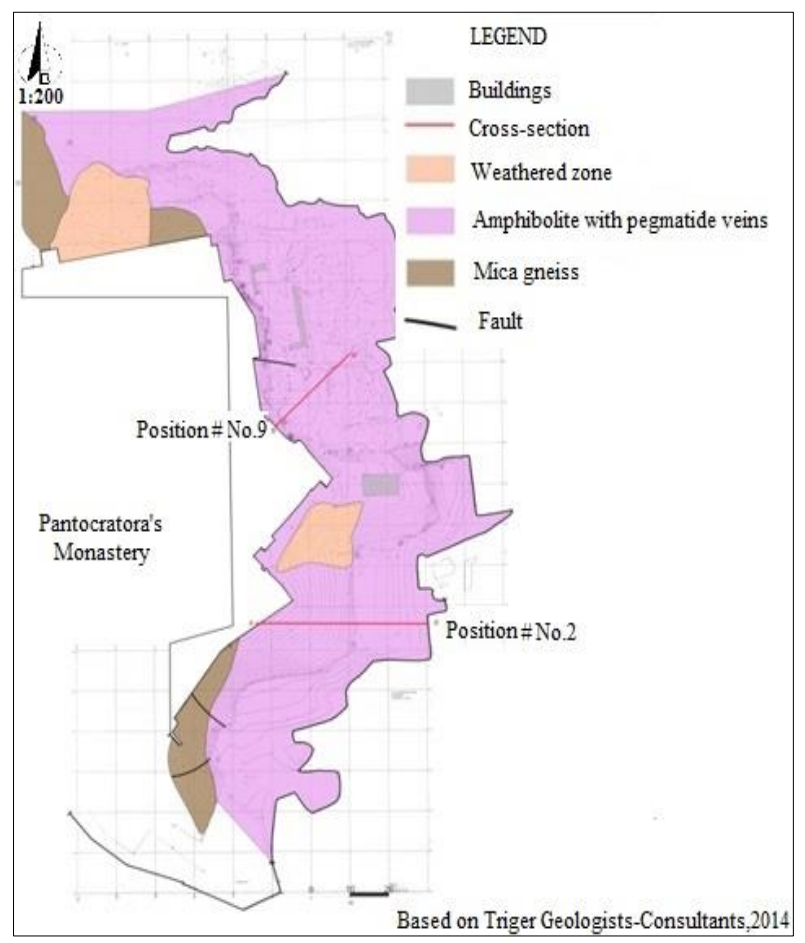

Figure 2 - A geological map of the site specific investigated area (Based on Triger GeologistsConsultants, 2014).

According to the new map of seismic hazard zones of the Hellenic Seismic Regulation EAK-2000, the Athos peninsula belongs to zone II with seismic acceleration $0.24 \mathrm{~g}$ with probability exceeding $10 \%$ in the next 50 years and the rocks are classified in Class A (rocky semi-rocky formations that grow in great breadth and depth, with no intense weathering).

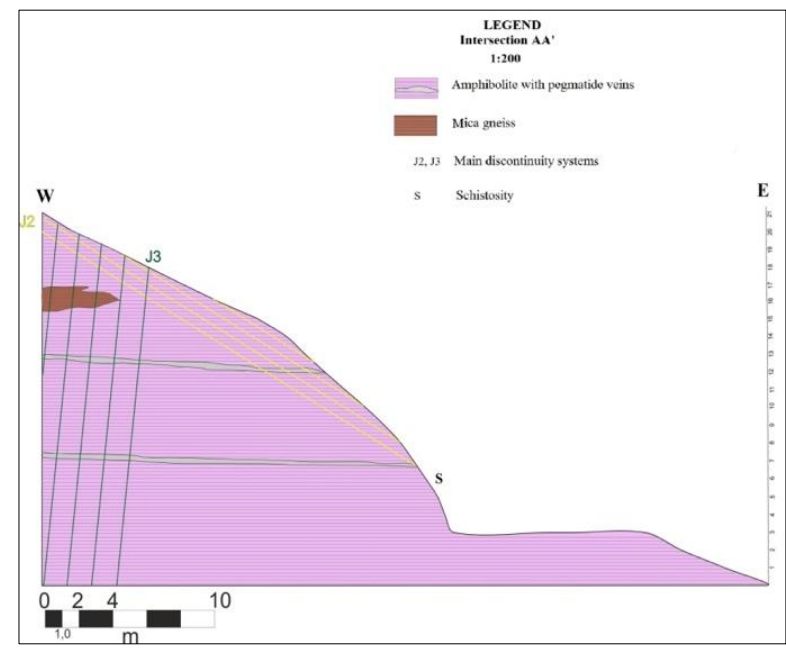

Figure 3 - Cross-section at location \#No.2(058 ${ }^{\circ} 096^{\circ}$ ) (Discontinuities are shown indicatively). 


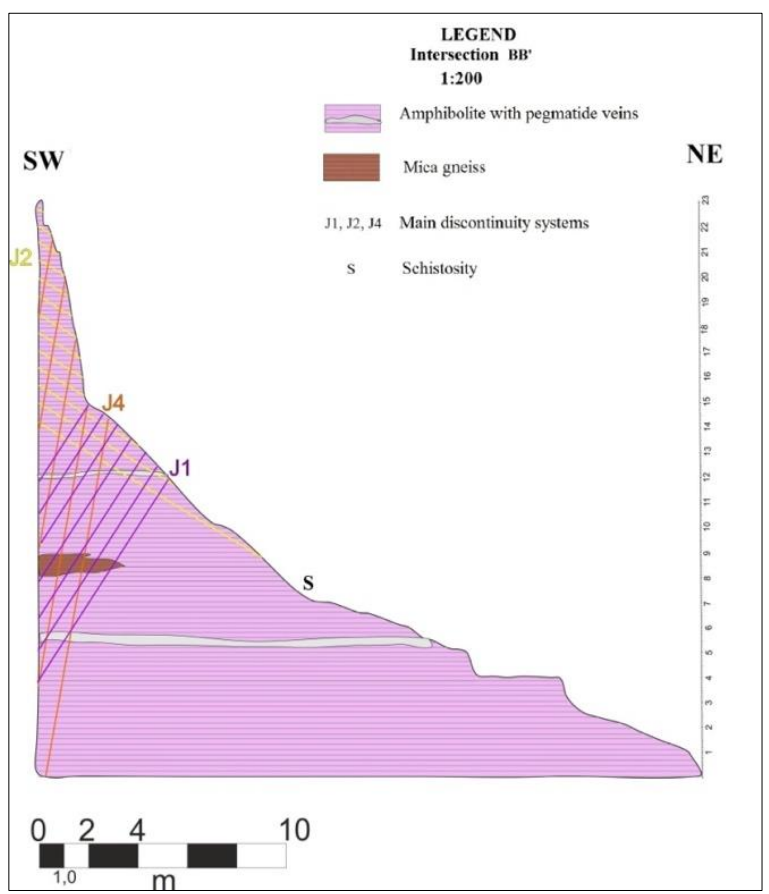

Figure 4 - Cross-section at location \#No.9(082\% ${ }^{\circ} 8^{\circ}$ ) (Discontinuities are shown indicatively).

Most earthquakes are shallow, not exceeding $60 \mathrm{~km}$ focal depth, and of low magnitude. According to the Geodynamic Institute of Athens the last 50 years seismicity was primarily of ML $<4$ and only in March and February 2012 two earthquakes occurred with a magnitude of 5.2 degrees.

\section{The LiDar technique and software tools}

The slopes were scanned by the terrestrial laser scanning (LiDar). The scattered light is collected by an optical lens and driven in the shooting and recording system. The output of the scanning is referred to as "point cloud" and consists of millions of points that represent a three-dimensional form of the respective surface. After the scan software that can process the point cloud should be applied. Each manufacturer usually includes their own software. For our investigation the Split-FX software (Split Engineering 2010) was used (Figure 5).

First the azimuth is defined at the point cloud depending on the angle of the laser beam during scanning and then the image output is purged from the "noise". Noise could be an object in front of the slope or an obstructing surface. As it can be seen at Figure 6 there is a scaffolding in front of the slope at location \#No.9 that has be removed when editing at Split-Fx software. Then the mesh parameters are defined, that is to say the number of points in each cell. Various mesh points were tested and it was estimated that the best mapping output was given at 15.000 points per cell, since a smaller number of them showed only few structures (discontinuities), while a greater number showed too many points that were no longer useful and editable.

The next step was to define all surfaces which form a specific discontinuity surface. This also depends on the set parameters. A minimum number of cells is required in the grid that can be grouped in order to create a discontinuity surface as well as a maximum angle of the side of a cell to its neighboring cell. For the two locations 10 cells was selected as the minimum number to create a discontinuity with a maximum angle of $10^{\circ}$. In many cases there are surfaces which are not parallel to the scanner so no discontinuities can be detected. In these cases, software allows for a manual discontinuity input. During this procedure Split-Fx indicated 179 discontinuities at location \#No.2 
and 208 discontinuities at location \#No.9 which is a large number of surfaces that with fieldwork would be difficult to be recorded, along the $30 \mathrm{~m}$ steep slope.

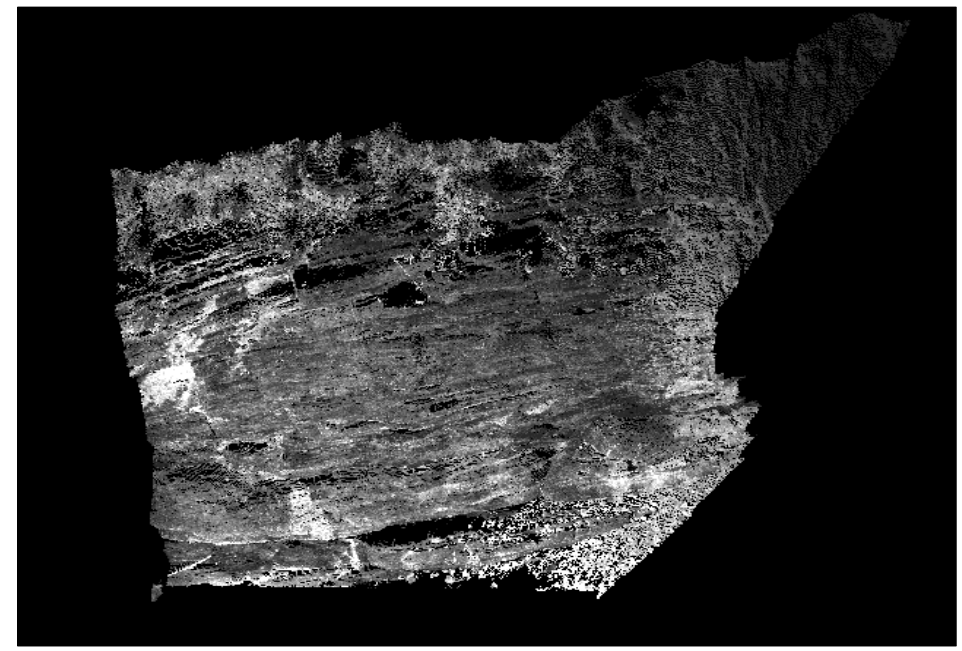

Figure 5 - The point cloud of a slope of the area as seen via Split-FX software (Split Engineering, 2010).

Subsequently it is essential to produce the main families of discontinuities. Discontinuities with similar dip/dip direction belong to the same group/family and have the same behavior at a potential failure. The Split-FX enables the use of a Schmidt stereographic projection. Figure 7 shows the final format of the point cloud after the above mentioned process at position \#No.9. Finally, the spacing of each set was measured which helps to override discontinuities that are superficial and give emphasis to persistent ones which influence most the slope stability. This helps also to estimate the volume of the potential rock blocks, which is beyond the scope of the present paper. Finally the spacing measurement gives a more realistic model of the slope.

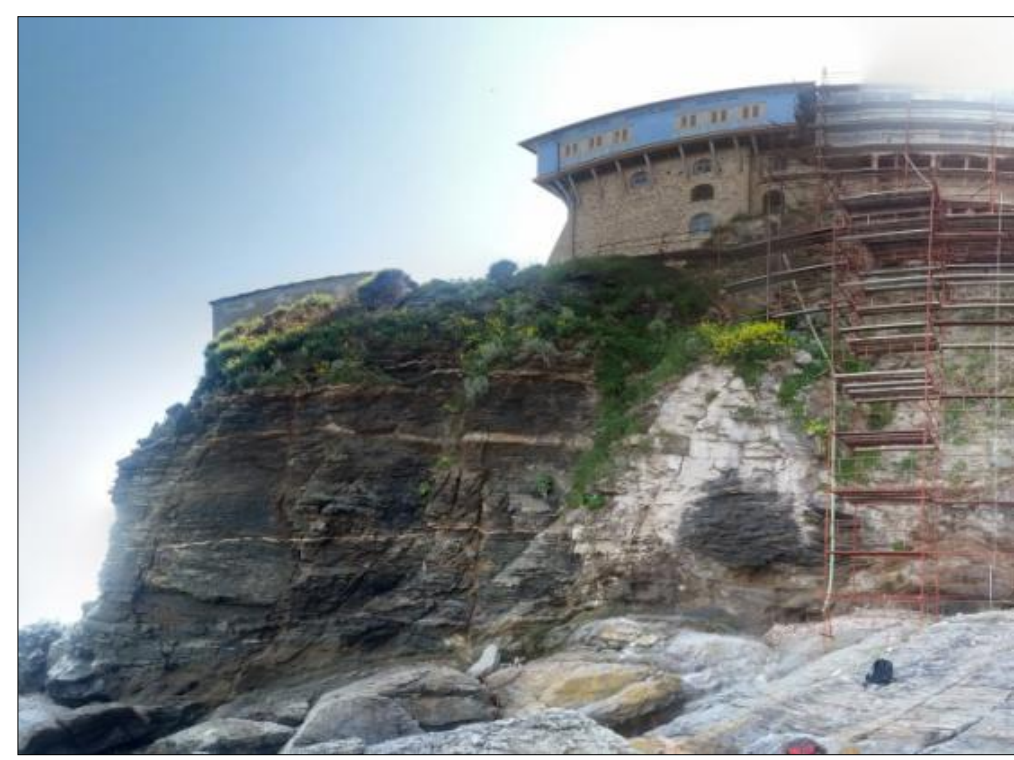

Figure 6 - Location \#No.9 (Triger Geologists-Consultants, 2014). 


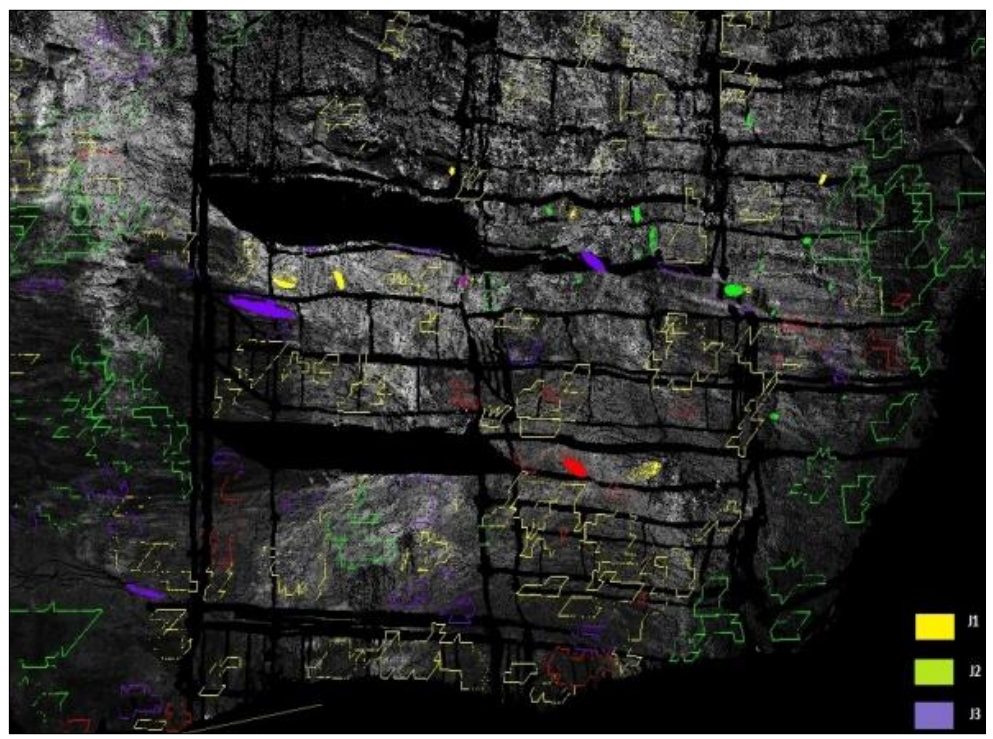

Figure 7 - Major planes of discontinuities as derived from Split-Fx.

The joint sets at this stage were evaluated in Dips 6.0 software (Rocscience Inc.) for further elaboration. Tectonic diagrams were created and major planes were detected again depending on the sets of discontinuities observed.

The friction angle of the discontinuities was estimated by the application of Barton criterion (1977) following field estimation of discontinuity roughness coefficient (JRC) and surface compressive strength (JCS) for each set of discontinuities (zero cohesion was applied to all discontinuity sets) (Table 1).

Kinematic analysis was carried out for every location so as to evaluate the potential failures. Location \#No.2 produced planar, wedge and flexural failures and direct toppling, while location \#No.9 produced wedge failure and direct toppling. Figure 9 shows an example of kinematic analysis at location \#No.9.

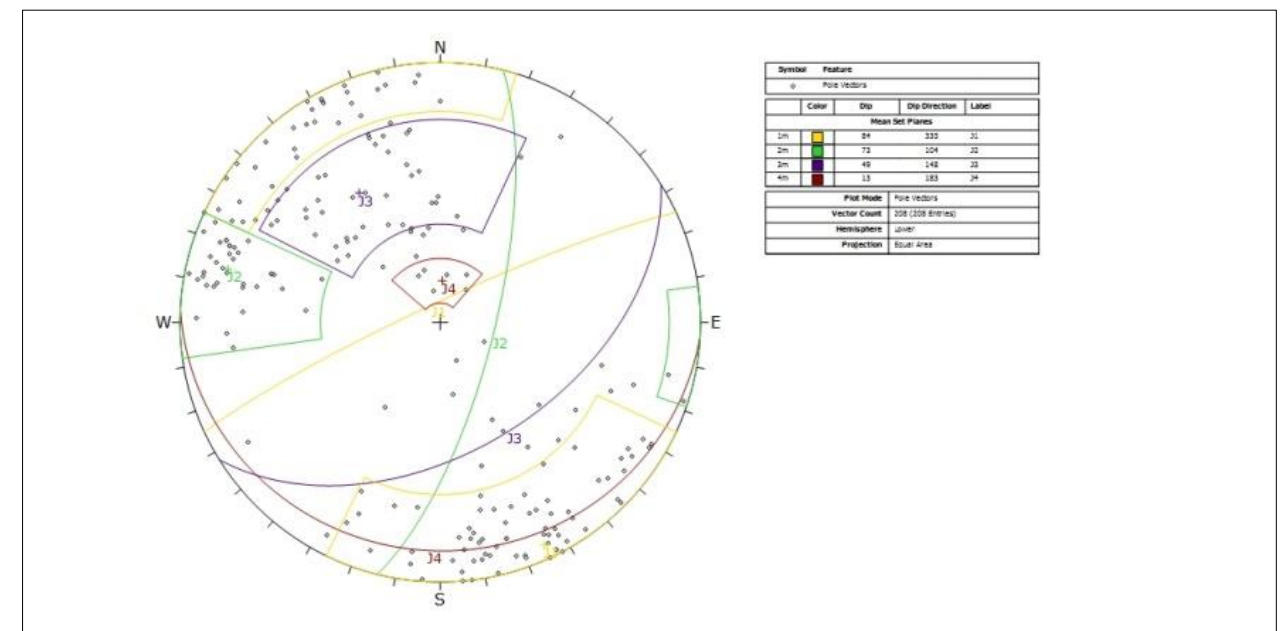

Figure 8 - Schmidt diagram showing the sets of discontinuities of the location \#No.9 as derived from Split-Fx. 
For the slope stability investigation RocPlane 3.0, Swedge 6.0 and Roctopple 1.0 of Rocscience software were used. It was obvious that in location \#No.2 safety factor is $<1$ only with the contribution of water and earthquake while in location \#No.9 a direct failure may occur even in dry and static conditions. Such failures have been recorded in the slope.

Table 1 - Parameters of Barton's criteria (fieldwork data) (Triger Geologists-Consultants, 2014).

\begin{tabular}{|ccccccc|}
\hline $\begin{array}{c}\text { Discontinuity } \\
\text { system }\end{array}$ & $\mathbf{J 1}$ & $\mathbf{J 2}$ & $\mathbf{J 3}$ & $\mathbf{J 4}$ & $\mathbf{J 5}$ & $\mathbf{S}$ \\
\hline $\boldsymbol{\varphi b}^{(\boldsymbol{o})}$ & 26 & 26 & 26 & 26 & 26 & 26 \\
$\mathbf{J R C}$ & 20 & 14 & 14 & 0,5 & 1,5 & 1,5 \\
$\mathbf{J C S}$ & 8,5 & 28,5 & 28,5 & 39 & 10,5 & 15 \\
$\boldsymbol{\varphi ( \mathbf { ( } ^ { \circ } )}$ & 37 & 42 & 42 & 27 & 27 & 27 \\
\hline
\end{tabular}

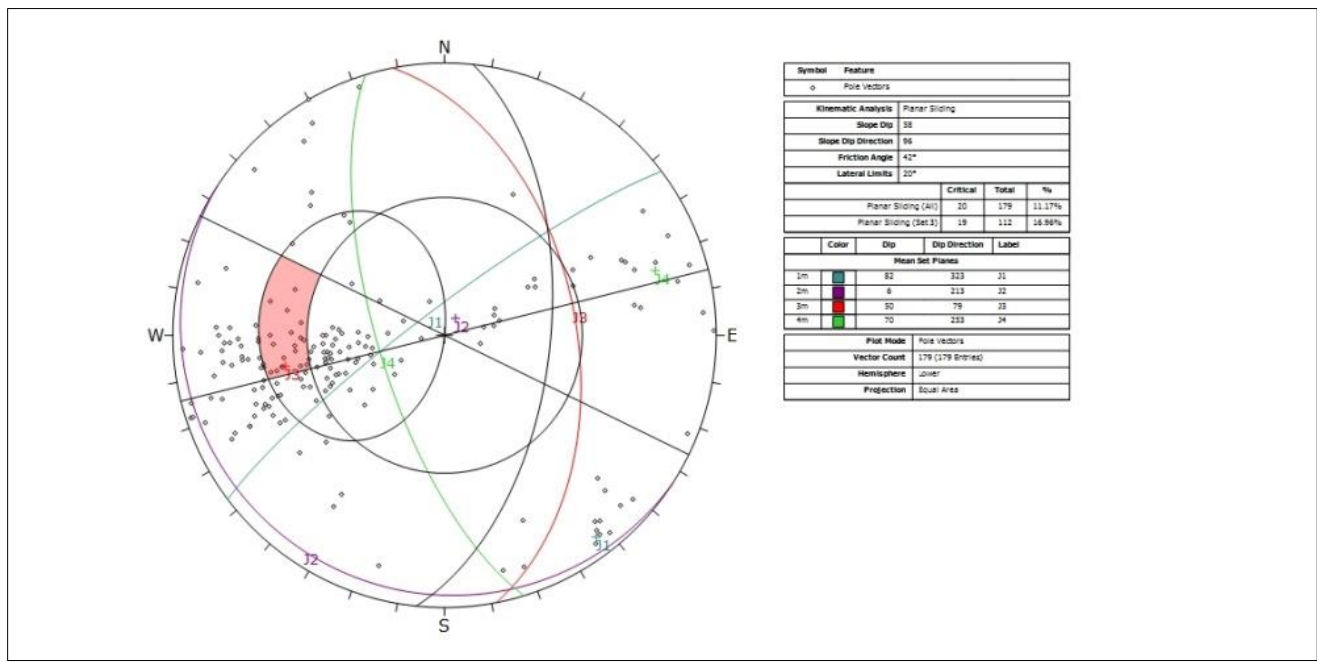

Figure 9 - Potential planar failure in location \#No. 2.

\section{Risk Assessment-Remedial measures}

The slopes are characterized by several possible structural instabilities due to external factors and of the steep topography as well as the unfavorable orientation of tectonic structures of rock mass in relation to the slopes.

These external factors that trigger failures in the area are:

- The erosion of the rock mass by the action of the sea and marine spray

- The seismicity

- The potential effects of the operation the Monastery such as the weight of the buildings, the sewage etc.

Heavy rain may also be a triggering factor, creating instantaneously a pressure in the fissures before the self drainage ability of the rock mass.

Another unfavorable factor is the existence of zones of greater weathering in the front of the slopes that cause undercuts which develop tensile tenses and eventually the loss of the strength and the failure. 
Based on the general morphology of the slopes, the mechanical characteristics of discontinuities of rock mass, the orientation of the major planes of discontinuities per position, the results of stability analysis, it was estimated that location \#No.2 is at moderate risk of failure while position \#No.9 at higher risk.

In the location \#No.2 it is recommended to scale down all the detached rock blocks, where possible, anchor the unstable blocks and protect the foot of the slope against erosion. In location \#No.9 similar measures must be taken but a main focus must be focused on the recovery of the prior geometry by extending the front to the east with the help of some retaining walls or gabions in order to make its dip as gentle as possible.

\section{Discussion}

The results of the present study were compared with actual field data collected. The correlation of the tectonic analysis was good, while the number of tectonic measurements was far greater. When compared to the fieldwork data it also shows that the method can be accurate as well as reliable. The sets of discontinuities derived from both methods (fieldwork and LiDar) have similar orientation and form the same major planes with slight deviations due to the accuracy of the azimuth adjustment. Slope stability analysis based on the fieldwork data as compared to the LiDar data, show more conservative results in the sense that field data give lower factors of safety for dry and static conditions (no water/no earthquake).

The two methods differ in the size of measurement data and processing speed. A significant advantage of the LiDar method is that most natural or artificial obstructions can be excluded without affecting the results of the analysis (physical barrier, poor visibility.). In addition LiDar technique gives you the ability to take measurements even if the area of interest is a high, steep and forested slope. Finally the measurement of the spacing of discontinuities is made easier thus helping to estimate the block volumes.

LiDar and its applications to engineering geology problems can be considered as a valuable supplementary tool for the investigation of the microtectonic structures and their elaboration for potential failure mechanism analysis. The estimation of slope instabilities in similar cases should always be done with the help of fieldwork and site investigation and the geological judgment of the results. The geologist should be aware of the limitations of the method and know when, where and why to use this technique. It is also very important to be able to test the quality of the information obtained and whether or not it reflects the actual conditions estimated via fieldwork.

\section{References}

Abellan, A., Vilaplana, J.M. and Martinez, J., 2006. Application of a long-range terrestrial laser scanner to a detailed rockfall study at Vall de Nuria (Eastern Pyrenees, Spain), Engineering Geology, 88(3-4), 136-148.

Barton, N. and Choubey, V., 1977. The shear strength of rock joints, Rock mechanics, 10(1-2), 1-54.

Bauer, A., Paar, G. and Kaltenbock, A., 2005. Mass Movement Monitoring Using Terrestrial Laser Scanner for Rock Fall Management. In: Geo-information for Disaster Management, In: van Oosterom, P., Zlatanova, S. and Fendel, E.M., eds., Springer, Berlin, 393-406.

Bellian, J.A., Kerans, C. and Jennette, D.C., 2005. Digital outcrop models: applications of terrestrial scanning lidar technology in stratigraphic modeling, Journal of Sedimentary Research, 75, 166-176.

Biasion, A., Bornaz, L. and Rinaudo, F., 2005. Laser Scanning Applications on Disaster Management. In: Geo-information for Disaster Management, In: van Oosterom, P., Zlatanova, S. and Fendel, E.M., Springer, Berlin, 19-33. 
Bitelli, G., Dubbini, M. and Zanutta, A., 2004. Terrestrial laser scanning and digital photogrammetry techniques to monitor landslide bodies, Proc. of the XXISPRS Congress Geo-Imagery Bridging Continents, Istanbul, Turkey, 246-251.

Kemeny, J., 2015. Application of Three-Dimensional Laser Scanning for the Identification, Evaluation, and Management of Unstable Highway Slopes, Transportation Pooled Fund Project TPF-5 (166) Final Report, 126 pp.

McCaffrey, K.J.W., Jones, R.R. and Holdsworth, R.E., 2005. Unlocking the spatial dimension: digital technologies and the future of geoscience fieldwork, Journal of the Geological Society, 162(2), 927-938.

Monserrat, O. and Crosetto, M., 2008. Deformation measurement using terrestrial laser scanning data and least squares 3-D surface matching, ISPRS Journal of Photogrammetry and Remote Sensing, 63(1), 142-154.

Mountrakis, D., 1985. Geology of Greece, University Studio Press, Thessaloniki, 208 pp. (in Greek).

Oppikofer, T., Jaboyedoff, M. and Keusen, H.-R., 2008. Collapse at the eastern Eiger flank in the Swiss Alps, Nature Geoscience, 1(8), 531-535.

Papantoniou, P. and Pitsis, Ch., 2008. The architecture of Agion Oros, Towers and Ports (in Greek), Undergraduate thesis, University of Patra, Greece, $227 \mathrm{pp}$.

Pavlides, S., Tsapanos, T., Koravos G., Michailidou, A. and Chatzipetros, A. 2010. Specific seismotectonic study of faults in the broader Kassandra mines region, Strategic Environmental Impact Assessment Preliminary Report, Hellas Gold S.A, Chalkidiki, Greece, 52 pp. (in Greek).

Pesci, A., Casula, G., Loddo, F., Bianchi, M.G. and Teza, G., 2009. Optech Ilris-3d Terrestrial Laser Scanner: Short User Guide, Technical report, 24 pp., Available online at: http://www.earth prints.org/handle/2122/5207.

Rosser, N.J., Lim, N, Petley, D.N., Dunning, S. and Allison, R.J., 2007. Patterns of precursory rockfall prior to slope failure, Journal of Geophysical Research: Earth Surface, 112(F4), doi: 10.1029/2006JF000642

Rosser, N.J., Petley, D.N., Lim, M., Dunning, S.A. and Allison, R.J., 2005. Terrestrial laser scanning for monitoring the process of hard rock coastal cliff erosion, Quarterly Journal of Engineering Geology and Hydrogeology, 38(4), 363-375.

Sagy, A., Brodsky, E.E. and Axen, G.J., 2007. Evolution of fault-surface roughness with slip. Geology, 35, 283-286.

Singh, B. and Goel, R.K., 1999. Rock Mass Classification: A Practical Approach in Civil Engineering, Elsevier, 46.

Slob, S. and Hack, R., 2004. 3-D Terrestrial Laser Scanning as a New Field Measurement and Monitoring Technique. In: Engineering Geology for Infrastructure Planning in Europe, A European Perspective, Hack, R., Azzam, R. and Charlier, R., eds., Lecture Notes in Earth Sciences, Springer, Berlin/Heidelberg, 104, 179-190.

Slob, S., Hack, R. and Turner, K.A., 2002. An approach to automate discontinuity measurements of rock faces using laser scanning techniques. In: Dinis da Gama, C. and Ribeiro e Sousa, L., eds., ISRM International Symposium on Rock Engineering for Mountainous Regions-Eurock 2002, Funchal. Portuguese Geotechnical Society, Lisbon, 87-94.

Triger Geologists-Consultants, 2014. Failure of the eastern rock slope of Pantokratoras Holy Monastery bedrock foundation, Technical Report (in Greek).

Umrao R.K, Singh, R., Ahmad, M. and Singh, T.N., 2011. Stability Analysis of Cut Slopes Using Continuous Slope Mass Rating and Kinematic Analysis in Rudraprayag District, Uttarakhand, Geomaterials, 1(3), 79-87.

Yousif, L.D, Awad, A.M., Ali, M.A. and Taufiq, U.A., 2014. The application of Rock Mass Rating and Slope Mass Rating systems on rock slopes of Al-Salman depression, South Iraq, Iraqi Bulletin of Geology and Mining, 10(1), 93-106. 